\title{
A Study on Cultural Characteristics of Taoist Clothing
}

\author{
Rong Yang ${ }^{1} \&$ Xiaoming Yang ${ }^{1}$ \\ ${ }^{1}$ College of Humanities, Donghua University, Songjiang, Shanghai, China \\ Correspondence: Xiaoming Yang, College of humanities, Donghua University, Songjiang, Shanghai, 201620, \\ China. E-mail: ynide@sina.com
}

Received: March 20, 2020

doi:10.5539/ass.v16n4p70
Accepted: March 28, $2020 \quad$ Online Published: March 30, 2020

URL: https://doi.org/10.5539/ass.v16n4p70

\begin{abstract}
Dress and personal adornment of Taoism, also short for Taoist Clothing. Its refers to the type of clothing with 'Tao' as the core concept. Taoist clothing as a kind of religious symbolic clothing, it can be described as a typical carrier of Chinese traditional culture (especially the Han nationality), which contains Chinese traditional religion, philosophy, aesthetics and technology. By studying the history, form and cultural symbols of Taoist clothing has important significance for help us to deeply understand Chinese traditional costume culture and to discover the valuable cultural elements contained in them.
\end{abstract}

Keywords: Taoism clothing, culture characteristics, Chinese traditional costume

Chinese costume is the cultural achievement created and accumulated by the laboring people in the long historical development of our country. The ancient Chinese costume is not only a carrier of material and cultural forms that can cover up the body and keep warm from cold, but also a symbolic manifestation of the traditional Chinese culture and its spirit. Therefore, the so-called 'Chinese costume culture' includes material and spiritual factors, which is the organic unity of the two. At the same time, it contains the comprehensive cultural elements of traditional Chinese science, philosophy, ethics, aesthetics, and technology.

The cultural essence of Taoist clothing is a kind of clothing system based on the faith and thought of 'Tao' and 'follows nature' in ancient Chinese society, which also contains the principle of 'original life of Tao'. There are three forms of Taoist clothing include Fairy Clothing, Taoist Rites of Clothing and Tao Priest's Daily Clothing: 1. Fairy Clothing is the regulation of the body symbol and idealized paradigm, which is generally presented in the theological images, allusions and narratives of Taoism or the imaginary world of Taoists. The basic design principle of Taoism's symbolic construction of immortal clothing is 'natural clothing' and 'body and clothing integration', which deeply reflects the thought of 'clothing is nature life'. Although Fairy Clothing is an imaginary dress symbol, it embodies the core life concept and Ethical Aesthetics of Taoism. It can be called the ontological design model of Taoism dress. 2. Taoist Rites of Clothing refers to the clothing worn by a Taoist in the process of holding a rites or practice. Taoist Rites of Clothing is a kind of ritual or ritualized clothing, its form not only has the cultural connotation of 'follows nature', but also reflects the strict ethical level characteristics of 'different grades, each with its own rites'. 3. Tao Priest's Daily Clothing is worn by Taoists in their daily lives. Its often takes the principle of 'dress shabbily in order to hide one's real worth' and emphasizes the simple aesthetic characteristics.

The form of Taoist clothing is complex, including three parts: head clothing, body clothing and foot clothing. Head clothing mainly includes Taoist crown, Taoist kerchief, etc.; the body clothing refers to Taoist robe, Taoist skirt, etc.; the foot clothing includes shoes, socks and so on. Taoist clothing emphasizes the 'natural' and 'immortal' characteristics in the design concept. In terms of the styles, colors, and fabrics of clothing, it emphasizes the differences from secular clothes and highlights the natural aesthetics of Taoism, which is natural and light. But on the other hand, Taoist clothing also absorbs the elements of secular ceremonial clothing, emphasizing the production principle of 'internal and external Taoist rites clothing must have a standard', strictly following the implementation of traditional Chinese etiquette and ethical principles. In general, Taoist clothing takes 'nature' as the fundamental aesthetic criterion, which reflects the spiritual temperament of Chinese aesthetics.

Historically, Taoist clothing is an important part of Chinese traditional costume culture, and plays a key role in the history of Chinese traditional costume. Taoism not only defines Taoist clothing as 'Chinese costume' 
(Dongxuan Lingbao qianzhenke) and 'Emperor's clothes' (Tianhuang zhidao taiqing yuce), but also does Chinese aesthetic and ethical design from the type, form, color and other aspects of clothing, which fully showing the spiritual connotation of Chinese culture. It can be said that 'Taoist clothing' is the symbolic costume symbol of the spirit of Chinese traditional culture. It is particularly noteworthy that Taoist clothing as the core carrier of Chinese costume culture, its connotation of Chinese traditional philosophy, ethics, aesthetics and technology, for the contemporary and future development of Chinese costume culture, it is still a valuable and worth exploring and using costume culture resources for the contemporary and future development of Chinese costume culture.

\section{What Is Taoist Clothing?}

It is worth noting that Taoism as the only large religion in China, is one of the roots of Chinese culture. In this way, Taoism has typical Chinese cultural characteristics in the concept definition, symbol design, cutting technology, style and temperament of clothing. In history, Taoism not only regards 'China' and 'mainland' as the place of life and a beautiful home, but also regards it as a place of peace and happiness. Ancient Taoists believed that 'China's Yang Qi is pure, making people believe in WuWei Avenue', (Dao Zang, Vol. 28, p. 413) 'the mainland is the blessed land of China, and the most precious country for human beings and heaven'; (Dao Zang, Vol. 17, p. 68) therefore, the people are all 'happy to live China' (fight against the earth collection). (Dao Zang, Vol. 25, p. 840) This can not be simply understood as a theory of cultural superiority, but Taoism's self-confidence and emotional expression of Chinese native culture. Based on a strong sense of Chinese culture, ancient Taoists defined Taoist clothing as 'Chinese clothing'. According to the Taoist scripture 'Dongxuanlingbaoqianzhenke', it is said that 'Taoist clothing is Chinese clothing, horizontal skirt and large sleeves, are different from the common'. (Dao Zang, Vol. 34, p. 371) This so-called 'clothing of Chinese' is the basic stipulation of 'Taoist clothing' from the nature of the country and culture. It can be said that 'Taoist clothing' is a kind of carrier of representation culture based on the traditional costume of ancient Chinese Han nationality and continues to this day. It not only keeps the costume form of ancient traditional Han nationality, but also keeps many elements of traditional Chinese culture. Of course, the most core and essential feature of Taoist clothing is the clothing expression of the thought and spirit of 'Tao'.

What is 'Taoist clothing'? It is undoubtedly extremely difficult to make a strict academic definition. It is generally believed that dress and personal adornment of Taoism is Taoist Clothing, also known as 'Taoist rites of clothing' and 'Taoism costumes', which are 'traditional costumes of the Chinese nation'; (Tian, 1994, p. 40) or it is believed that 'Taoist rites of clothing are one of the books by which Taoism can communicate with gods, which has been injected into a kind of religious ethical connotation by history'. (Jiang, 1995, p. 119) However, this does not generalize the cultural essence and specific characteristics of Taoist dress. Here, this paper intends to make a more comprehensive, extensive and in-depth investigation.

In my opinion, the core essence of Taoist costume is 'Tao'. However, 'Tao' itself is an abstract concept. How does it embody the concept of dress? In fact, 'Tao' is the definition of the real existence of life itself. In the sense of human life, 'Tao' refers to a state of nature, freedom and health. The concept of 'Taoist clothing' is essentially a dress symbol and its expression form based on this concept of life, rather than just 'Taoist priest dress'. (Zhang, 2010, p. 93)

Historically speaking, the most core principle of the life concept on which Taoism costumes are based is: 'the clothing of nature'. The meaning of this concept is that the essence of 'clothing' is the existence and spontaneous expression of life itself, rather than being erected by externally prescribed symbols. In other words, Taoism, unlike even Confucianism, does not regard 'clothing's color' as a symbol of demarcation or sectorial social class; it emphasizes more that 'clothing' is the embodiment of the existence of life itself and its value. It shows the essence of Taoist clothing concept of Taoism, and it is also that Taoist clothing concept is more authentic and universal than Confucian clothing concept.

Taoism has a more specific expression of 'clothing of nature', that is, 'born in nature' and 'body clothing in one body'. The so-called 'born naturally' means: 'Natural beauty formed into clothes, nine-colors of light are born everything. Length and size, should be shaped according to the situation; or bright eight light round like hole, the sun's far and near change naturally; or nine-colors synthesis makes all things be shine; or dragons and phoenixes, colorful landscape all changing.' (DaoZang, Vol. 24, p. 727)

In this paper, 'clothes' is regarded as the 'formation' of natural. In fact, the essence of 'clothes' is to equate 'clothes' with life itself, and express the life essence of 'clothes' with a theological rhetoric. In this way, Taoism, when it comes to clothes, especially the ideal 'immortal clothes', connotes such a principle idea of clothing, that is, 'the integration of body and clothes'. The so-called 'body clothing integration' refers to that the body is the 
internal entity of the clothing, while the clothing is the external form of the body, which presents a consistent and even integrated relationship. This principle, of course, is a theological expression; however, its ideological essence actually points to the life noumenon of Taoist dress symbols. Based on this, we may make the following definition of Taoist costume ('Dao-Fu'): The so-called 'Dao-Fu' refers to the cultural symbol system of clothing, which is based on the concept and spirit of 'Tao', reflecting and reflecting the existence of life 'nature' and its value and aesthetic feeling. It is not only a kind of real clothing type, but also a kind of idealized clothing cultural symbol system.

\section{The Cultural Characteristics of Taoist Clothing}

It needs to be emphasized that 'nature' refers to that life is in its own real existence state. This state, of course, is an unrealistic and ideal existence. But it just reflects the cultural value attitude and position of Taoist clothing: the pursuit of the existence of dignity, beauty and value of life itself. This is exactly against the hierarchical color system of Confucianism. In this way, the cultural characteristics of Taoist clothing are as follows:

\subsection{The Nature of Life}

The essence of life refers to the state of freedom, harmony and perfection of human life, that is, the so-called 'natural' state of Taoism. Therefore, Taoism's 'natural' ideal is embodied in its dress form and symbol, which is the dress presentation of life body, and thus includes the shaping and regulation of the dress's quality, color, pattern, and its corresponding aesthetic concept, aesthetic style and other contents.

It is particularly noteworthy that Taoism uses 'Qi' as the basic element of life, so all life forms exist in the state of 'Qi'. This concept of life is critical to the essential definition of Taoist costumes. From the perspective of Taoism, the true state of life is exactly a harmonious, spiritual and vivid 'Dao-Qi'; in this way, the iconic form of 'Dao-Fu', namely 'vitality' and 'harmony' such as. In other words, 'Dao-Fu' corresponds to a 'Qi' harmonious body or a living organism, and because of its Yin, Yang, form and spirit harmony, it presents life signs of lightness, elegance, and charm. In this way, 'Tao-Fu' expresses and presents the authenticity of life in the form of clothing.

\subsection{The Richness of Life}

Taoism is not as simple as people think, pursuing simple clothes. In fact, this is due to the requirement of being a monk in the state of monasticism: emphasizing that in the process of monasticism, you cannot be tempted by external material desires and pursue worldly fame and status. Therefore, the monk wears 'coarse cloth' to express his opposition to the concept of nobility and class. However, 'coarse cloth' itself is not the spiritual essence of 'Tao'. The spiritual attribute of 'Tao' to clothing is the bloom of nature's nature, richness, and strength. Therefore, on the interface of 'Dao', 'Dao-Fu' is displayed in gorgeous, colorful, and even fantasy forms. This form of clothing, on the one hand, is contained in fairy costumes in the form of ideas or spirits, and on the other hand, it is presented in legal clothing in a realistic and standardized form. However, as far as the social impact of its clothing is concerned, Taoist clothing's aesthetic concept of emphasizing the abundance of life has a profound impact on the pursuit of natural liberation, even luxury and beauty of secular clothing.

\subsection{Ethical of Life}

The 'nature' of Taoist clothing is not an 'freedom' that is arbitrary and unregulated, but a symbol that simultaneously contains the content of ethical realms such as life and rank: 'Taoist rites of clothing as like official court robe, there is a different rank $\cdots \cdots$... someone wears coarse cloths, skirt and scarf, the length of their production, the number of seams, each has a quasi-type, so it is called Taoist rites of clothing. ' (DaoZang, Vol.24, p. 781) In this regard, Jiang Sheng pointed out: 'Taoist rites of clothing is also a sign of the difference between believers' internal ethical order and fairy rank, and it is a reflection of the ethical order and aesthetic sentiment in reality in the religious field. (Jiang, 1995, p. 120)

However, it should be noted that although the Taoist law suit is 'a cultural symbol that consolidates and solidifies ethical values, it is a highly integrated embodiment of ethical values and ethical order.' (Jiang, 1995, p. 120) But Taoism has 'reduced' these ethical symbols to the ontology or value of life-that is, to revert the essence of these clothing-level symbols to an expression of the foundation and procedural existence of life Instead of using 'clothing's color' mechanically and solidly as the definition and mark of social utilitarianism or hierarchy as Confucian. Based on this, Taoist costumes transform the Confucian hierarchy and moral rank into a life order and life process to reflect the upward ethical aesthetics of the upward flow of life.

\section{Conclusion}

The above three characteristics of Taoist clothing show that the cultural connotation of Taoism clothing has 
profound life philosophy and social ethics. The essence of 'Dao-Fu' is to take 'nature' as its principle. It advocates that clothing embodies the true value of life. It does not take simplicity as its spiritual traits. As far as its type is concerned, Taoism's daily clothing and Taoist rites of clothing are the clothes of spiritual practice. They are not the essence of Taoism, and the purpose is the 'Fairy clothing'. In other words, 'Fairy clothing' is the symbolic form of clothing that truly embodies the spirit of 'Tao' and 'nature'.

\section{References}

DaoZang (1989). vol.17[C], Cultural Relics Publishing House, Shanghai Bookstore Publishing House, Tianjin Ancient Books Publishing House. p. 68.

DaoZang. (1989). vol.24[C], Cultural Relics Publishing House, Shanghai Bookstore Publishing House, Tianjin Ancient Books Publishing House. p. 727, 781.

DaoZang. (1989). vol.25[C], Cultural Relics Publishing House, Shanghai Bookstore Publishing House, Tianjin Ancient Books Publishing House. p. 840.

DaoZang. (1989). vol.28[C], Cultural Relics Publishing House, Shanghai Bookstore Publishing House, Tianjin Ancient Books Publishing House. p. 413.

DaoZang. (1989). vol.34[C], Cultural Relics Publishing House, Shanghai Bookstore Publishing House, Tianjin Ancient Books Publishing House. p. 371.

Jiang, S. (1995). The ethical value symbols of Taoism dress. Chinese Classics Culture, (4), 119-120.

Tian, C. Y. (1994). Daoism costume. China Taosim, (1), 40.

Zhang, Z. Q. (2010). An Exposition and Analysis of the Phenomenon of Literati and Scholar-officials' Putting on the Taoist Robes in the Northern Song Dynasty. Studies in World Religions, (4), 93-105. https://doi.org/10.3969/j.issn.1000-4289.2010.04.011

\section{Copyrights}

Copyright for this article is retained by the author(s), with first publication rights granted to the journal.

This is an open-access article distributed under the terms and conditions of the Creative Commons Attribution license (http://creativecommons.org/licenses/by/4.0/). 